\title{
Defending Eliminative Structuralism and a Whole Lot More (or Less)
}

\author{
Steven French \\ School of PRHS, \\ University of Leeds
}

\begin{abstract}
Ontic structural realism argues that structure is all there is. In (French 2014) I argued for an 'eliminativist' version of this view, according to which the world should be conceived, metaphysically, as structure, and objects, at both the fundamental and 'everyday' levels, should be eliminated. This paper is a response to a number of profound concerns that have been raised, such as how we might distinguish between the kind of structure invoked by this view and mathematical structure in general, how we should choose between eliminativist ontic structural realism and alternative metaphysical accounts such as dispositionalism, and how we should capture, in metaphysical terms, the relationship between structures and particles. In developing my response I shall touch on a number of broad issues, including the applicability of mathematics, the nature of representation and the relationship between metaphysics and science in general.
\end{abstract}

Keywords: causation, dependence, disposition, metaphysics, object, representation, structure

I'd like to thank Anjan Chakravartty, James Ladyman, Johanna Wolff and Otávio Bueno for such constructive and profound critical commentaries. We've all engaged with these and similar themes over the years but seeing them expressed in such a balanced and insightful fashion has helped me bring them into focus and revealed further aspects I'd previously overlooked.

Let me begin by outlining my view of the relationship between realism and metaphysics which may help situate the form of ontic structural realism (OSR) I defend in French (2014 - hereafter 'my book' - and also illuminate, in particular, the differences between myself and Ladyman on this issue.

Elsewhere (French 2018a) I have argued that realists should not be content with adopting a 'shallow' form of their stance, as represented by expressing a belief in the existence of electrons, say, and leaving it at that. Motivated by 'Chakravartty's Challenge', as described by Bueno, I suggest they should go 'deep', metaphysically speaking, and draw on the various devices that metaphysics makes available in order to offer a clearer picture of what that belief in electrons consists in. Such devices range widely in form and reach, from the Principle of Identity of Indiscernibles, for example, previously thought to be ruled out by quantum mechanics but, arguably, resuscitated through the notion of 'weak discernibility' (Saunders 2003), to various accounts of dependence and 'ground', or the determinable-determinate relationship. However, as Ladyman notes, adopting an object-oriented metaphysics in this context, with the associated 'devices', will bring the realist up against the infamous underdetermination of metaphysics by the physics, in the form in which I have presented it (repeatedly): 'electrons are individual objects' and 'electrons are non-individual objects', both of which are compatible with quantum mechanics 
(QM) and both of which can be 'fleshed out' by means of metaphysical devices as mentioned above ('weak discernibility' has been deployed to help make sense of the claim that electrons are individuals and forms of non-standard set theory have been presented as a framework in which to understand the claim that they are non-individuals; see French and Krause 2006). Now the realist must face a further challenge, posed by van Fraassen (1989) - how can she say 'how the world is', when, to use this example, she can't even say whether the electrons she apparently believes in are individuals or not?

The response of the ontic structural realist is to suggest that we should simply discard the metaphysics of objects that underpins this underdetermination (Ladyman 1998). What then to put in its place? One answer would be 'nothing', but that takes us back to the 'shallow' view. Another would be to look to the theories of physics themselves but here I acknowledge that I was previously too quick in suggesting that we should just 'read our metaphysics off' such theories (as Chakravartty has noted). Rather I would say now that we should look to our best theories in order to identify those prominent and central features that can then be metaphysically 'fleshed out' in order to respond to Chakravarty's Challenge and yield a 'clear picture' of how the world is. And if we look to the theories of modern physics what stands out, in particular, are certain laws and symmetry principles, where the latter are presented via the mathematics of group theory; that is, what stands out are certain structures. Now, again, the realist could stop there and when asked what it is she is a realist about, she could simply point to such structures, as set out in textbooks or scientific papers, and say "That! That is what I am a realist about."

However, that could lead to the impression that she is being a realist about the mathematics via which these structures are presented, thereby adopting some form of structural Platonism (see French and Ladyman 2003 for an early response to this misattribution). How then can that impression be avoided? Or, to put it another way, how can we distinguish the physical from the mathematical? The answer obviously bears on Wolff's concerns about whether the structuralist can take the mathematician's abstract view of structure and hopefully what I say here will help to resolve those concerns. In my book (Ch. 8) I used Tegmark's work (Tegmark 2006) as a foil to try to bring this set of issues into sharp focus. And in particular, what I found interesting about that work was the way that Tegmark dismisses diverse attempts at grounding the above distinction as appealing to just so much 'metaphysical baggage'. Bueno has nicely homed in on this contrast to raise a number of pertinent concerns. However, let me say from the start that insofar as I am seeking to distinguish my view from Tegmark's, I am more than happy to avail myself of (at least some of) the various criticisms that Bueno raises about the latter.

Having said that, I'm not so sure that Tegmark couldn't wriggle out from under them. So, although, as Bueno notes, isomorphism does not imply identity, the example of the different structures of the odd and even numbers may not be entirely compelling. In that case we have access (in whatever sense you prefer) to both number structures and can clearly distinguish them. But when it comes to the mathematical structures that Tegmark is concerned with and those unobservable and fundamental features of the world to which he claims those structures are isomorphic, we have no such access, at least not in the case of the latter. And of course if we were to insist that such features are 'clearly' not 
identical to the mathematical structures he would likely respond that this is to beg the question, and that those aspects of these features to which we might want to point to establish the distinction constitute the afore-mentioned 'metaphysical baggage'. My own view is that to adequately respond to Tegmark, we need to push back on that dismissal that the distinction between mathematical and physical features is just so much metaphysical baggage. However, to do that we need to establish which pieces of this 'baggage' underpin what we take to be 'physical' and that, as I indicate in that chapter, is not so straightforward.

Likewise, although I would certainly appreciate an argument that rules out Tegmark's position on the grounds of incoherence with regard to its modal implications, I'm not sure that appealing to the Banach-Tarski theorem does the trick. I suspect that Tegmark might respond that such an appeal rests on an understanding of the distinction between mathematical and physical possibility that begs the question against him! And after all, prior to 1935, say, we would have said that it is not physically possible for a cat to exist in both 'alive' and 'dead' states - of course, we might still deny this but the point is that the development of modern physics with its incorporation of such 'high-level' mathematical structures has raised questions about the above distinction.

As for the principle of plenitude, I should emphasise that $I$ introduced this in order to push Tegmark's account as far as it could go. Again, this is not to admit that I agree with his approach but, as I said, I wanted to present it as a foil to OSR in order to highlight the difficulty in pinning down this crucial distinction between the physical and mathematical. Having said that and although I agree that mathematics 'contains' many more structures than we currently seem to need to represent the world, a note of caution must still be sounded: we do not know which of these currently 'surplus' structures may turn out to be useful for future representations. Consider the situation in the early-mid 1920's: at that time, at least as far as those working on the emergent quantum physics were concerned, group theory was just so much high-level, abstract mathematics, but then along came Weyl and Wigner who showed how it could be deployed to represent atomic and nuclear systems (see Bueno and French 2018). From Tegmark's point of view, the world is actually group-theoretical and since if we were going to designate anything as 'physical', the actual world is surely a candidate, then the possibility represented by these group-theoretical structures in the early-mid 1920s must also be physical. And so, again, the very thing that Bueno and I have emphasised in our most recent work together, namely the significance of 'surplus' structure for the applicability of mathematics, provides further grist for the Tegmarkian mill!

How then to escape it? In the book I argued that although, as Ladyman notes, OSR can accommodate causal notions, appeals to 'thick' forms of such notions do not get off the ground, for all the well-known reasons having to do with the difficulties in articulating accounts of causality in the context of modern physics (specifically, in the contexts of both quantum theory and General Relativity; at best, it seems, physics supports only a 'thin' notion of causation understood in terms of certain dependencies). And leaving aside such difficulties, Tegmark would again dismiss these notions as just so much 'metaphysical baggage'. Perhaps ultimately we may be able to do no more than point out that only certain of these mathematical structures get 'hooked up', via various 
interpretational devices, to empirical observation, also folded into the structure on the Cassirerean picture that I favour (and here again Ladyman and I disagree, since he takes the 'phenomena' to be non-structural). But Tegmark could still say that as 'existential witnesses', to use Jessica Wilson's felicitous phrase (2012), such observations in effect allow us to pick out the actual from the possible (similar sentiments can be found elsewhere; see for example Lowe 1998, p. 9), which is different from distinguishing the physical from the mathematical. For me that's enough and it may be that, as I said again, Ladyman, in his work with Don Ross (Ladyman and Ross 2007), is right that the latter distinction shouldn't be given the significance we assign to it.

Returning to the challenge, then, even if we insist that the structure we want to be realists about is physical and not mathematical, there is still the question of what it is, metaphysically speaking. Here there is a further clarification to be made, which is illuminated by Bueno's comments. We might further explicate our insistence by maintaining that group theory, for example, as interpreted in the context of the relevant physical theory - the Standard Model, for example - represents those features of the structure of the world exemplified by the relevant symmetries. There is now the question of how we should characterise that representational role and answering that will help clarify another concern that Bueno has raised.

In (Bueno and French 2012) he and I proposed the partial structures variant of the so-called Semantic Approach as an appropriate framework for understanding the nature and role of various kinds of representational devices theories, models, diagrams and so forth - in science. However, granted Bueno's point about the significance of the role of the user in taking such devices to be representations to begin with, it is not clear to me that this in itself has particularly far-reaching implications for realism. When it comes to intentions, I've argued that these should not be taken to be constitutive of the representational relationship (contrast this with, e.g., Suarez 2009); rather, they are what can be appealed to in order to pick out a particular such relationship from the plethora available. So, in the case of a work of art such as a painting, what a viewer takes it to represent may differ from what the artist intended it to represent. When it comes to science, at least, such an appeal to intentions, and to users more generally, does not imply - or at least not without further steps in the argument - that we are 'picking out' or constructing reality itself. At most, such an appeal - as it stands - can be invoked in support of the claim that our theories and models represent certain aspects or features of 'reality'.

Likewise, simply acknowledging that representations are typically perspectival does not imply any abandonment of realism as standardly understood, unless that notion of 'perspectival' is freighted in a certain way (see Massimi 2018). I would take the term as synonymous with 'partial' and repeat my further insistence that the partial structures approach offers the best account in this regard. And as da Costa and I and Bueno have also repeatedly emphasised, such an approach can be put to effective use by both realists and anti-realists. In particular, the pragmatic aspects alluded to by Bueno - having to do with the specifics of our methods of enquiry - can be understood more or less strongly more, in a way that can be captured by a pragmatist theory of truth, which leads to a particular kind of stance (I'll leave to one side the extent to which it might 
still be described as 'realist'), or less, in a way that does not conflict with 'standard' forms of realism.

Relatedly, this may help illuminate what Bueno finds epistemologically problematic about the notion of 'structure', in the sense that, as he puts it, structures are supposed to be representational but also independent of us, as users of such representations. Perhaps the difficulty lies with some ambiguity associated with that word. There is the world-as-structure as a physical entity, for want of a better word; there is the mathematical structure deployed in our theories by means of which we represent that world-as-structure; then there are the partial structures that, at the 'meta-level' of the philosophy of science (or philosophical reflection on our mathematical and scientific practices more generally) we use to represent those theories. Hopefully if we keep those different meanings distinct, the epistemological difficulty will evaporate. In particular, according to the realist, as typically understood, the world-asstructure is independent of us (and I would hope the structural empiricist would agree, even if she insists that we cannot know what that world-as-structure is 'really' like; and one can relax or reconceive that independence, along neoKantian lines, perhaps, as Cassirer does, or in phenomenological terms or whatever); but that world-as-structure is not itself representational. The mathematics is, and the partial structures are, but they are not independent of us, or at least not in the relevant sense; that is, we choose which such representational devices to deploy, at the levels of both scientific and philosophical practice.

With that out of the way, we can return to Chakravartty's Challenge and articulate a structural realist understanding of how the world is in terms of an appropriate metaphysics of structure. In doing so, we run the (epistemic) risk of having to adopt what Langton calls an attitude of humility towards the outcome of that articulation, since the metaphysics will inevitably take us beyond the physics (here we find ourselves in the situation nicely set out by Chakravartty, in his recent book (2017)).

The way forward, I argue, is to adopt a kind of two-stage process: we begin by dropping the metaphysics that the physics cannot support - in this case, the metaphysics of objecthood, given the above underdetermination - and then begin to elaborate the metaphysics that is consonant with our best theories. Here again, Ladyman and I differ. He famously eschews current metaphysics as conservative, based on, at best, a high school understanding of science and thus as inappropriate for the needs of the structural realist. However, in the book and in subsequent publications with Kerry McKenzie (2012 and 2015), I've presented another option that regards metaphysics as offering a range of resources, such as the devices indicated above, to be appropriated and deployed in the service of our structuralist programme. The alternative is to construct some form of bespoke metaphysical framework but that's a huge task, and the historical precedents are not encouraging (here I'm thinking of Eddington's later work for example; 1946).

To illustrate this appropriation and deployment, let's consider the concern that has been raised about the existence of derivative or nonfundamental entities. Not for nothing is the view I defend characterised as eliminativist ontic structural realism! I press for the elimination of not only objects at the fundamental level, but at all 'derivative' levels, adopting a form of 
nihilism towards tables, dogs, people and so on. On my view, all there is in the world is structure, understood as that fundamental structure presented to us by modern physics. This, of course, is often portrayed as a hard line to hoe, not least because of the need to accommodate all the apparently true claims we seem to be able to make about such 'derivative' entities. But as I spell out in the book, the apparent costs of such a nihilistic attitude can be mitigated by deploying one of several tools that modern metaphysics makes available to us.

So, we can continue to hold as true certain statements made by physicists about particles, say, or those made by us about tables and chairs in our 'everyday' lives by adopting Horgan and Potrç's theory of truth: 'there are tables' is true, in their sense of indirect correspondence, under the contextually operative standards governing everyday usage but 'there are no tables', in the sense of fundamental entities, is also true under those standards that apply in the case of direct correspondence, which involves the standard Tarskian account of truth (Horgan and Potrç 2008). Alternatively, if you prefer not to be so revisionary with your semantics, you might prefer Cameron's truth-maker theory, according to which 'there are tables' may be taken as true, not because there are actually tables, but because of the fundamental features of the world the structure in my view - that make such statements true (Cameron 2008). It should come as no surprise that there are many such metaphysical devices, developed by monists and nihilists and those revisionist metaphysicians in between, that may be repurposed by the structural realist.

But in rifling through the toolbox, we may also find metaphysical devices that the object-oriented realist can likewise repurpose. Such is the case with dispositionalism, as developed in particular by Chakravartty in his (2007) and more recently as advocated in his (2017). It is worth noting here that in certain respects our accounts are not so different, and as I suggest in the book (Ch. 9), eliminativist OSR can even be seen as a kind of reverse engineered dispositionalism. So, the latter begins with objects, which are then taken to be the seats of power-ridden properties, which in turn are inter-related, and these inter-relationships are then conceived as law-like. The former, in contrast, begins with those inter-relationships, from which the properties 'drop out' and the clustering of these properties may then be conceived of as (putative) 'objects'. And both accounts are, or can be construed as, eliminativist: OSR with regard to objects, dispositionalism with regard to laws (at least according to Mumford 2004, for example). The difference in effect amounts to a difference of ontological direction, but still, that's difference enough for ontological dispute!

So the question then, as nicely posed by Chakravartty, is on what grounds should we choose one over the other?

As he notes, we might situate the question in a broadly naturalistic context and argue that one view meshes better with current physics than the other. Thus I have argued elsewhere that dispositionalism, as standardly understood, does not fare so well in this context (see French forthcominga; also French 2017 and 2018b). Now a lot hangs on that phrase 'as standardly understood' - I've cashed it out in terms of the well-known 'Stimulus and Manifestation' characterisation, whereby a disposition is identified in terms of the manifestation that results from a particular stimulus. And I've argued that it is difficult to see how such a characterisation can find any purchase within modern physics (see also Psillos 2006). Many examples that are given in support 
of it are either highly idealised or rely on transparently classical principles. So, for example, we might be invited to think of charge as dispositional by imagining a charged object, towards which we bring another charged object; here we have a stimulus - the bringing in of a test charge - resulting in a manifestation - the attraction or repulsion that the test charge feels. But, as I argue, this is not how properties such as charge are seen in the modern context. In particular, it is difficult to see how dispositionalism can accommodate the nature and role of symmetries. Bird makes a good fist of showing how we obtain Coulomb's Law, for example, from a dispositional standpoint (Bird 2007; although even this can be questioned, as Vetter notes - Vetter 2009) but gives up entirely on going on from there to symmetries, preferring instead to hope that future physics will have no need for them.

Now, as Chakravartty notes, the dispositionalist need not be wedded to this characterisation. Thus he has suggested that the manifestations of dispositions may be relational in nature, where such relations comprise the concrete structures about which we should be realists (2007; here and below I'm repeating what I say in French forthcominga). Similarly, Heil argues that a disposition's manifestation should be understood as a 'mutual manifestation of reciprocal disposition partners'. On this view we can think of the S\&M characterisation as yielding a kind of relational 'net', again inviting an obvious comparison with structuralism (Heil 2005). Nevertheless, concerns remain over whether this sort of move can accommodate the role of symmetries as constraints, or meta-laws, or more generally as relations between relations. The issue is how we get up to the 'next level' as it were, from manifestations-asrelational to symmetries understood as relations between (lawlike) relations.

One option would be edge even closer to the structuralist and shift the seat of the dispositions from the objects to the laws. However, it is even less clear how the S\&M analysis would apply - what would be the stimuli in such cases leading the laws to manifest the relevant symmetries? Alternatively, one could package up the laws and symmetries together, in the sense that the manifestation, under the S\&M analysis, should be understood not just as relational, in the way that Chakravartty and Heil suggest, but as second-order relational in that it includes the relations between relations that come to be categorised as symmetries. In other words, the disposition yields the relevant law and symmetry as a bundle. An attractive feature of such a proposal is that it might explain why symmetries and laws are bound so tightly together in terms of their both deriving from the same source, namely the relevant disposition. However, more work clearly needs to be undertaken to develop the details within the dispositionalist framework.

A further option, as Chakravartty suggests, would be to view symmetries in terms of dispositions of the world, taken as an entity or object in and of itself. As he says, that doesn't appear to be so different, ontologically speaking, from taking symmetries to be features of the structure of the world. But, again as I argue in French (forthcominga), it is not clear what the relevant property would be that would be decomposed into the appropriate dispositions. If that property is taken to be 'being the world' then we would have one property associated with myriad different dispositions, yielding (somehow) all the different symmetries. Alternatively, if the relevant properties of 'the world' are taken to be those associated with the relevant laws, then one would have to wonder what the 
invocation of the world-as-object is doing when it is the laws that are the actual seats of the relevant dispositions. Furthermore, if it is 'the world' that is taken to possess the relevant dispositions, with the symmetries as manifestations, then one has to wonder, again, what the associated stimuli could be. Clearly, in this case, shifting the seat of the dispositions but retaining an object-oriented approach undermines the S\&M analysis.

Of course, as he notes, not all dispositionalists accept that analysis and there are further alternatives in the toolbox. Thus, Vetter (2015) for example, takes dispositions to be individuated by their manifestation conditions alone and argues that dispositional ascriptions are naturally paraphrased via expressions of possibility, the localized counterpart of which is potentiality $(2015, \mathrm{p} .23)$. Thus the relevant sense of modality is best characterized (to a first approximation) by ' $x$ can $M$ ' (where this should be understood as graded and context-sensitive). In French (forthcominga and 2017) I've made my 'Viking' move and appropriated this as a possible means of capturing the modality I see as inherent in the world-as-structure. Thus we could read Vetter's ' $x$ can $M$ ' as ' the structure contains certain possibilities', or possesses certain potentialities, just as Permutation Symmetry contains more possibilities than the Bose-Einstein and Fermi-Dirac statistics that we observe in this the actual world, and thus there is the potential - fleetingly realised in the 1960s - for non-standard statistics to be manifested (I'll come back to this). Again, viewed in this light, dispositionalism and structuralism are not so far removed from one another. Having said that, Chakravartty is right in emphasising that they differ with regard to their attitude towards objects. Here there is certainly an issue when it comes to what we take to be an object. In the book I suggested it could be anything that has what Brading and Skiles (2012) call an 'individuality profile'. Thus even if you were to adopt a 'bundle' account of objects, we would differ insofar as I would insist that the cluster of properties that drop out of the relevant symmetries should not be understood as a candidate for such a profile. Here I would suggest that eliminativist OSR is more parsimonious in obviating any need to establish such a profile but I acknowledge the complexity and fragility of such weighings. ${ }^{1}$ Both the modal structuralist and the dispositionalist accept that there is modality in the world, in some sense, and they differ in that regard only as to where that modality should be situated (in the book I suggest that this is like pushing down a bump in the carpet!). The dispositionalist allocates it to powers, seated in objects, whereas the structuralist assigns it to the laws and symmetries. In these terms the latter view does not seem to be more parsimonious. Still, by eliminating objects, it does seem to reduce our commitments and although the dispositionalist might be able to say something similar if she could follow Mumford in eliminating symmetries along with laws, I've sketched the difficulties in doing that.

Now perhaps the dispositionalist can broaden the notion of object so as to blur the difference with structuralism and undermine this parsimony claim. Thus, just as some dispositionalists have moved away from the S\&M characterisation, emphasising manifestations only, or dropping it altogether, so they might also adopt the 'Umbrella View' of objects, according to which every thing is an object (Rettler and Bailey 2017), and so structures may also count as

\footnotetext{
${ }^{1}$ Here I must acknowledge the work of Leeds PhD student Fabio Ceravolo in this regard.
} 
'objects'. Here we see another example of the appropriation of metaphysical 'devices, this time on the part of the dispositionalist. However, as relaxed as I generally am about such moves, if we broaden things too far then we lose the sense of a foil to structuralism that the object-oriented approach offered. As close as certain forms of dispositionalism are to structuralism we need to retain some sense of 'otherness' if the two perspectives are not to fold into one another!

And of course, one difference is encapsulated in Chakravartty's insistence that objects, events, processes etc are all traditionally thought to 'have' properties - its that sense of 'having' or possessing that I want to resist. In a nutshell, I don't see the need for properties to be possessed by something in this way and I would argue that this traditional way of thinking has been supplanted by what modern physics, as embodied in the Standard Model, now tells us. Of course it is difficult to eschew this traditional way of thinking entirely. Chakravartty rightly notes that when it comes to the contexts of detection and experimentation and manipulation we naturally talk and think in terms of particles possessing certain properties, which offers a 'bottom up' framework in which we can explain their behaviour.

However, I think we need to be careful not to let this natural talking and thinking dictate our ontological commitments. As I said above, physicists naturally talk of particles, especially when discussing the latest results from the Large Hadron Collider, say, but it doesn't straightforwardly follow that we should ground such talk in an object-oriented ontology, especially after taking on board what Chakravartty calls the 'top-down' considerations that motivate the adoption of Ontic Structural Realism. As Décio Krause and I noted (2006), drawing on the work of Toraldo di Francia, there is a kind of 'pseudoindividuality' that is assumed in measurement situations, perhaps because of the inherent spatio-temporal localizability of observations. This then underpins an assumption of object-oriented ontology but attempts to export that ontology across the line drawn by the so-called 'measurement problem' in QM run into the ground for all the reasons rehearsed in both books. Thus, just as I would argue that we should reconceive 'particles' in structuralist terms and draw on the variety of metaphysical devices that are available to appropriately render 'natural' talk, so I would claim that Chakravartty's bottom-up framework is ultimately derivative and the ontology underpinning it, eliminable.

That's not to say that I entirely dismiss the well-made point that physics involves a multiplicity of practices, although I suspect the picture may be more one of 'lifts' and 'façades', somehow collaged together along the lines of Mark Wilson's account of classical mechanics (Wilson 2006). Indeed, I draw on just such a picture in my forthcoming eliminativist view of theories themselves (French forthcoming b). However the relationship between such a view and realism is, if not subtle, then not entirely straightforward and certainly I think that describing a field in terms of a multiplicity of practices is consistent with holding to a unitary fundamental ontology. Nevertheless, the point is well taken: again, it is not enough for me to insist that we can just read that ontology off the physics, given that 'the physics' is so multifaceted (and in this regard, the 'rainforest realism' proposed by Ladyman together with Don Ross (Ladyman and Ross 2007) may be more to many people's taste). Having said that, I would still maintain that certain of these practices relate to what can be designated as 'fundamental' physics and that, granted all the caveats Chakravartty raises about 
such 'reading off', if we have any pretensions to naturalism, the nature and role of symmetries at that fundamental level must be taken seriously, in both metaphysical and, crucially, explanatory terms.

Chakravartty rightly raises the concern as to how the sense of explanation here is to be cashed out. In a recent work, Juha Saatsi and I have suggested that Woodward's counterfactual account can be extended to accommodate this sense, as the different possibilities encompassed by these symmetries allow us to entertain 'what if things had been different?' scenarios (French and Saatsi 2018). So, for example, when it comes to Permutation Symmetry, we can reflect on 'what if electrons had been parafermions?' for example, keeping in mind that such a possibility is not so outré when it comes to quarks at least! And what we would get is very different statistical behaviour. So following the Woodwardian line, the claim is that we can explain the behaviour of electrons in terms of their being fermions. Now, this does not answer the additional question 'why do we observe only bosons and fermions and not any of the infinite variety of their 'para-' cousins?' One answer might be that the latter are not physically possible and that the relevant representations of the Permutation Group represent merely mathematical 'surplus' structure. However, the history of quark physics, when such representations were deployed early on (see French 1995) suggests we should be cautious about such excising moves (see again Bueno and French 2018). Alternatively we might draw on the details of that history and note the subsequent dominance of the alternative account of quarks as regular fermions but with an additional property, now known as 'colour', an account that blossomed into quantum chromo-dynamics. As Chakravartty notes, Baker et. al. have argued that from a quantum field theoretic perspective, the difference between describing quarks in terms of colour and considering them as parafermions of order three is merely one of convention (a suggestion that was actually 'in the air' during the history of these developments; see French 1985). On that basis, we might insist that we do, in fact, observe parafermions, at least those of order three, but we choose to describe them as coloured quarks.

Nevertheless, that still leaves all the other para-kinds 'hanging there', as it were, and the question returns, why do we not see any of these?

As Chakravartty also notes, my response is quite blunt: because that's the world we live in! But then he wonders why the symmetries succeed in doing whatever explanatory work they do in some cases but not others. Here, perhaps, we need to be careful in spelling out what that work is. So, consider the (quite) well-known example of the halting of the collapse of a white dwarf star (French and Saatsi 2018). That halting is the relevant explanandum and the explanans is typically taken to be Pauli's Exclusion Principle, which 'drops out' of Permutation Symmetry. The dependence that holds here is then tracked counterfactually within the Woodwardian account and in terms of such a framework we can see how the symmetry does explanatory work. One could of course suggest that white dwarf stars have a disposition to behave in such a way under gravitational collapse but that sails awfully close to a 'dormitive virtue' scenario. Or one could suggest that electrons have a disposition to arrange themselves in a way that can be described in terms of the anti-symmetric representation of the permutation group. However, not only does that introduce additional ontology, we lose the unificatory aspect of the explanation provided by the umbrella of Permutation Symmetry covering both electron and photon behaviour, for example. 
That's one way in which, I would argue, symmetries do explanatory work. However, that's not the work that Chakravartty is concerned with: here the explanandum is the observation that we only see fermions and bosons but no paraparticles. I can't see how dispositionalism can help us; of course, if there are no paraparticles then there are no dispositions to behave according to parastatistics (and that behaviour is startlingly different from that of 'standard' quantum statistical mechanics; see French 1987). But the question is, why are there no paraparticles to begin with? My response above may seem too blunt but recall, the kinds of properties that we observe in this world, such as positive mass, half-integral and integral spin, as well as that corresponding to bosonic and fermionic kinds, can also be regarded as 'existential witnesses', to use Wilson's term, in the sense that they pick out the actual world from the allowable possibilities.

Having said all of that, and in facing up to 'Chakravartty's Challenge' and pursuing an answer to the question 'what is this structure that you speak of?' there is still the core worry that the eliminativist answer that I am trying to articulate - namely that the structure I speak of is one that is without objects - is in tension with the very representational device - namely group theory - used in these explanations.

Wolff expresses this worry in her consideration of what I have called the Poincaré Manouevre. As expressed in (French 2014, p. 67), this states that

Although we might introduce the terminology, or perhaps better, symbology, of objects as part of our representation of the relevant structure, these should be regarded as mere devices that allow us to construct, articulate, or appropriately represent the relevant structure, and any representational priority they might have should not be taken to imply that they are ontologically foundational.

An obvious and fundamental problem faced by any revisionary metaphysics, and by eliminativism in particular, has to do with what stance one should take with regard to the terms and the putative entities they refer to, when one wants to eliminate the latter, given the use made of the former. This problem becomes particularly acute in the present context, given the role of mathematics and the nature of its set-theoretical foundations - at first glance it might seem that objects are effectively cemented into the very basic mathematical descriptions employed in physics. Thus take group theory, again, deployed to represent, within our theories, the symmetries that I take to be a constitutive feature of the structure of the world. As Wolff notes, group theory describes the transformations between elements, which thus appear to be ineliminable. How then can the structural realist point to such features of modern physics in support of her view while at the same time insisting on the elimination of objects?

As I indicate in the book, this is an issue that structuralists of various stripes - such as Eddington, Cassirer, Weyl and yes, Poincaré - have had to deal with in elaborating their respective positions. Eddington, for example, argued that the group-theoretic elements and the transformations could not be separated, metaphysically at least, but had to be taken together as a package, yielding his 'moderate' form of structuralism. But then when thinking about spin and our understanding of it, he argues that we may begin with an entity and 
consideration of how it is transformed under rotations, but then once we have those transformations, set out in tabular form, say, we may disregard the entity and focus instead on the group-theoretic transformations themselves and the 'patterns' they display (and here is a link to Ladyman and Ross 2007). This seems to me to be a manifestation of the same manoeuvre used by Poincaré in considering the Erlangen group-theoretic approach to geometry: we begin with a set of entities - triangles, say - consider certain transformations that may hold between them, and then shift our metaphysical focus to those transformations, discarding the entities we begin with, or, more moderately perhaps, downplaying their metaphysical status, in the sense of according them lower ontological priority, as Eddington did when it came to group-theoretic 'elements'. The entities, originally conceived, can then be regarded as no more than a heuristic device, or a form of 'Wittgenstein's ladder' - useful to 'get' us to the transformations, which I take to describe the relevant structure, but which can then be discarded or ejected from our metaphysical pantheon.

On an autobiographical note, I thought of this while getting off the bus near my house, with Otávio Bueno, as he was pressing me on precisely this issue of the apparent ineliminability of objects (and Poincaré and buses go well together when it comes to heuristics!) but more generally, this can also be cast in terms of another appropriation of devices and manoeuvres from their relevant historical and metaphysical contexts. In performing this act of appropriation, not all of the relevant context is brought forward with the device. Thus, even though for Poincaré that context incorporated a distinction between form and matter, the structuralist, in appropriating Poincaré's Manoeuvre, is not required to accept that particular distinction. Which is not to say that the distinction she is concerned with, namely that between object and structure, may not be akin to or bear some resemblance to that between matter and form. Speaking for myself, however, I think the latter becomes problematic in the context of modern physics and even more so when it comes to structuralism if it is taken to be related to the further distinction between concrete and abstract. As I suggest in the book, I don't find that particularly helpful.

Thus, just to wrap up, I take the Poincaré Manoeuvre to be just that, a manoeuvre, which Poincaré uses for certain purposes in what is basically a mathematical context and which I then appropriate and use for my own purposes in what is basically a metaphysical context. (One could argue that such manoeuvres and devices are so context dependent that they can't just be ripped out and used willy-nilly in this way, but that's a whole different argument we could have!)

More acutely perhaps, Wolff questions the metaphysical grounds for adopting an eliminativist stance in this context to begin with. Let's recall that in the face of the underdetermination between quantum particles as individual objects and quantum particles as non-individual objects, the structural realist suggests that you pull in your metaphysical horns, as it were, and insist that quantum 'particles' should not be regarded as objects in the first place. What are they then? Well, first of all, the 'they' here refers to whatever it is that lies behind/gives rise to/however you want to put it, those features that physicists attribute to the behaviour of 'particles'. Which features? Consider the beautiful curves carved out in a bubble chamber, for example. These might be attributed to something of a certain mass and a certain charge passing through the imposed 
magnetic field. What is it that binds together these properties, such that we get this behaviour? Standardly, the answer would be a 'particle', understood, within the framework of an object-oriented metaphysics, as an object, whether individual or non-individual. ${ }^{2}$ So the structural realist needs to be able to account for that 'binding' together of properties - what Chakravartty calls the 'sociability' of such properties - and she can, by noting that they 'drop out' of the symmetries, described by group theory - such as the Poincaré group for example. It is in this sense that 'particles-as-objects' come to be reconceptualised as features of structure; that is, those features that lead physicists to invoke 'particles', which most metaphysicians and realists then understand as objects, are 're-situated', if you like, as features of the more fundamental structure, as captured by the relevant group.

Given this relationship between the particles and the symmetries, I argued that the former are such that in order for them to exist, necessarily a certain kind of structure has to exist. So, for example, in order for an electron, as an entity of a certain mass and a certain charge and a certain spin to exist, that aspect of the structure of the world described by the Poincaré group has to exist. Wolff focuses on my attempt to capture that relationship in terms of the wellknown metaphysical relation of essential dependence. Here again the 'toolbox' approach is invoked, in an effort to show how certain standard metaphysical devices may still be of use. However, Wolff argues that it is not clear that even were such a relationship to hold it would allow one to claim that the putative objects had been eliminated. Here she gives the example of her (essential) dependence on the existence of her parents; granted that dependence, it does not follow, she insists, that there is no more to her than the fact that she is her parents' child and that she can, as a result, be metaphysically eliminated.

One reaction this argument would be to admit that my attempt to deploy essential dependence in this context has failed. Perhaps this notion is simply inappropriate in the context of modern physics and we should try to elaborate a bespoke metaphysics or alternatively 'go shallow' and eschew metaphysics entirely. But I think that admission would be a little too quick and I'm not convinced by the counter-example Wolff gives. In her case, it is true that even given her dependence, genetic and otherwise, on her parents, she still exists. But what if every property of Wolff depended on those of her parents? Well, of course we would still be inclined, I hope, to say that she exists, since we can ostensively identify her and distinguish her from her parents by her spatio-temporal location. But that's not an option in the quantum context. In that context, if Wolff were an electron (!), everything that makes her an electron, her very constitution as an electron, is dependent on the relevant structure. That is why I said that there is nothing to quantum entities, like electrons, that is not cashed out in terms of the structure. Wolff insists that essential dependence does not yield this conclusion. Again, I could respond 'well, so much for essential dependence then!' But I think I should say that the notion of essential dependence I have in mind is perhaps 'thicker' or more robust than the one Wolff is appealing to.

\footnotetext{
2 One could go deeper, metaphysically speaking and insist that this 'binding' derives from either some form of substratum or, in the case of so-called 'bundle' accounts of objects, some notion such as 'compresence'. Both options have been subject to extensive critical discussion and a further advantage of the structuralist account is that it allows us to sidestep the whole debate. (Thanks to Darrell Rowbottom for pointing this out.)
} 
However, she argues that if such a notion were deployed, it would have to hold between objects and something else, where quantum mechanics itself shows that that something else does not exist. And, she continues, it is unlikely that any such something can be found, given the above underdetermination argument. So, in particular, if one were to insist, as some do, that to be an object one must be an individual and quantum mechanics rules out individual objects, then we can just point to the other horn of the underdetermination and say that one can have non-individual objects. Indeed, in general, it is difficult to see how quantum mechanics, as a theory of physics, could rule out the relevant metaphysical principle or feature on which objects, metaphysically conceived, could depend. Thus I am hoist by my own metaphysical petard!

But that is precisely why I think that sort of argument is not a good way to go. It is better I think to argue that those features that lead physicists to posit the existence of 'particles' and metaphysically inclined philosophers (and physicists) to conceive of those 'particles' as objects, are dependent, in whatever sense, on the structure (as manifested in terms of the relevant symmetries) and thus the metaphysical positing of objecthood is superfluous and can be done away with. The 'moderate' structural realist insists that this positing is not superfluous at all, that even taken to be 'thin' entities, we need objects to pin down our structure in some sense. But that's where I struggle to make sense of this 'pinning down'. Indeed, I see that insistence as simply the result of cleaving to particular forms of metaphysics coupled with certain formal frameworks (as noted above with regard to the Poincaré Manoeuvre) and given that, I have argued, these non-superfluous objects are not so much 'thin' as utterly empty, at least from a metaphysical perspective (see French 2014 pp.178-181).

Now is this 'doing away with' of objects vindicatory or non-vindicatory, to use Wolff's helpful distinction? Wolff thinks the kinds of explanation that invoke essential dependence as above are vindicatory, in the sense that they explain why things in fact appear as they do, whereas what is needed is a nonvindicatory explanation, in the sense of explaining away the appearance of certain facts. The example from meta-ethics of the error theorist explaining away the universality of ethical judgments in terms of subjective psychology is useful here. But again we need to tread carefully: the explanation of those features that are attributed by physicists to particles is certainly vindicatory. We explain why certain properties cluster together in the way that they do by invoking the relevant symmetries; in doing so, we don't 'do away' with those features.

So what is it about objects that leads to them being 'done away with' by quantum mechanics, or more broadly modern physics as represented by the Standard Model? I would suggest that it is their role as a kind of fundamental locus, or seat, whether of causal powers (as Chakravartty has maintained; 2007) or for the instantiation of properties (as Psillos has emphasised, 2016). It is in this sense, perhaps, that we can understand their role in pinning down structure for the moderate structural realist. But, I would argue, again, that this gets the 'direction' of world construction the wrong way round: as in the case of dispositionalism, here we start with the objects, then add causal powers or properties, between which there hold relations that are then understood as lawlike and so on; whereas what the role of symmetries pushes us to acknowledge is that the direction should be reversed, so that we begin with the symmetries and laws, from which the relevant properties effectively 'drop out' (as we've already 
seen, this shift in direction can be used to characterise the differences between structural realism and dispositionalism). The clustering of those properties is then accounted for by those symmetries and laws - that is, by (the relevant features of the structure of the world - without any need for objects as some kind of seat or locus. Just as the error theorist explains away universality in terms of subjective psychology, so the eliminativist ontic structural realist explains away this role of objects in terms of the fundamental symmetries.

When it comes to so-called 'ordinary' objects, on the other hand, I agree that there is more room to manoeuvre for the object-oriented metaphysician. One could argue that although there are no objects at the quantum 'level', there are at the level of the 'everyday', supporting that argument with an appropriate understanding of 'level' and an equally appropriate account of the formation of objects from (in whatever sense) their non-objectual components. Wolff asks how I would respond to the structural emergentist, who adopts eliminativism at the fundamental level but allows for the emergence of objects at some 'higher' level. I think my response would have to be a version of the motto of the Great State of Missouri: 'Show me!'

Less bluntly, there would need to be a suitably detailed account of that sense of 'emergence' that ties the metaphysics at the appropriate joints to the relevant physics. One possible framework for such an account might be that of Barnes (2012) who has argued that the distinction between the fundamental and the derivative should be 'pulled apart' from that between the ontologically dependent and independent. With such a separation, emergence can then be understood in terms of that which is ontologically dependent yet also fundamental. So, for example, someone could argue that although the relevant features of chairs, tables, and so on are ontologically dependent on the structure of the world, in the way that their solidity for example is dependent on Permutation Symmetry, chairs, tables and so on can still be regarded as fundamental. It seems to me that there are some interesting paths to travel within such a framework but I would still be reluctant to regard chairs, tables and so on as objects, for precisely the reasons sketched above. To be regarded as such, metaphysically, they would have to be understood as the seats of powers, as that in which properties are instantiated etc., and that understanding runs into direct conflict with the metaphysical picture I've drawn from the physics the solidity possessed by my chair can't both be dependent on Permutation Symmetry as a feature of the structure of the world and instantiated in the chair qua object.

As for Wolff's concern whether the relevant explanatory dependence is causal, it should be clear now that it is not (when she wrote her comments Wolff was not of course aware of the further work presented in French and Saatsi 2018). Again, we track the relevant dependencies by exploring the counterfactual possibilities encoded in the symmetries (as represented grouptheoretically). However, note how the scope of the possible here is constrained within this structuralist picture - in French (2014) I hint at how the construction of possible worlds will have to be different when considered from this perspective. So the Lewisian model based on permuting elements of the actual world is not going to work when those elements are taken to correspond to the fundamental putative 'objects' of modern physics (and here, and elsewhere, some of my concerns sidle up to Bueno's). With objects eliminated, the usual 
basis for world construction is no longer available; instead one has to begin with the actual world-as-structure and consider how that might be different, as indicated above with regard to Permutation Symmetry.

Metaphysicians may insist that these issues have to do only with physical possibility and that they are free to sail across the wide seas of modality. Kerry McKenzie and I have expressed an attitude of bemused indulgence about such voyages (French and McKenzie 2012 and 2015): on the one hand, we're happy to make instrumental use of whatever devices our metaphysician friends bring home from such trips; on the other, if the intention is to say something meaningful about the actual world, then appropriate consideration needs to be taken of the relevant physics and the constraints it imposes.

So, for example, we often find, in discussions of the metaphysics of laws for example, consideration of a possible world in which there exists only one particle, a proton, say. But, again, as Kerry and I have pointed out, it is not clear that such a possibility is even allowed by the Standard Model (2012). Now consider the question: is it possible to have atoms, as they are in actuality, without Permutation Symmetry? An immediate answer might be 'No!', since without Permutation Symmetry we wouldn't have the Exclusion Principle and without that, we wouldn't have atoms, at least not as we know them. You might argue that we could have something that functions like the Exclusion Principle, without dropping out of Permutation Symmetry, or that the latter itself turns out not to be fundamental but derives from some broader feature (something that is quite likely in the context of developing accounts of quantum gravity) but at the very least we need to step carefully and include appropriate caveats into our modal musings.

Thus, when Wolff asks whether ordinary solid objects are necessarily such that they exist in virtue of these symmetry features, we need to likewise move with appropriate caution. Of course, we can imagine or conceive of a possible world of objects moving according to Newton's laws but does that correspond to a 'genuine' possibility or what Leibniz called a 'chimera'? We have to ask the question: are these objects composed of atoms and are the latter as we currently think of them? If so, without Permutation Symmetry they won't be 'solid' and with it, the world won't be Newtonian! So if possibility amounts to no more than mere conceivability then in that sense Newtonian 'worlds' are not ruled out; but if possibility is appropriately naturalised then the set of such worlds is appropriately cut down. Indeed, the constraints may squeeze tight enough that there remains only one world, the actual one (see Bird preprint). Whether this amounts to a modal disaster or not depends on the purposes of such discourse if we want to speculate in a philosophically light-hearted manner then what's the harm in letting our imaginations run wild?! However, if we're engaged in serious naturalistic metaphysics, as I take it we are here, then our modal reflections must be appropriately tailored to what we've learned about the world.

Returning to emergence, even if an appropriate account could be given, I think that as in the contrast with dispositionalism, the choice would come down to competing ideologies: eliminativism at the fundamental level + emergence + everyday objects and our usual theory of truth or eliminativism across the board + some non-standard account either of truth per se or of the relationship between truth makers and truth bearers or some other device, in terms of which our beliefs and utterances about 'everyday' objects can be accommodated, as I 
indicated above. The former retains our usual semantics but pays for the privilege in terms of some kind of levels-based ontology plus a suitably nuanced account of emergence, whereas the latter requires some careful thought with regard to the truth of 'this chair is solid', for example, but has the advantage of ontological paucity across the board. Again, the kinds of considerations of parsimony that Chakravartty has concerns about might be brought to bear but here I shall only say 'You pays your money and you takes your choice'!

Let me conclude by thanking again all four commentators. If I were to write the book again, in the light of these concerns, it would, I think, come out a very different animal and much better for it.

\section{References}

Barnes, E. (2012), 'Emergence and Fundamentality', Mind 121, pp. 873-901.

Bird, A. 2007. Nature's Metaphysics: Laws and Properties Oxford: Oxford University Press.

Bird, A. (preprint), 'Time, Chance and the Necessity of Everything', forthcoming.

Bueno, O. and French, S. (2012), 'How Theories Represent', The British Journal for the Philosophy of Science 62, pp. 857-894.

Bueno, O. and French, S. (2018), Applying Mathematics: Immersion, Inference, Interpretation, OUP.

Eddington, A.S. (1946) Fundamental Theory. Cambridge: Cambridge University Press.

French, S. (1987), 'First Quantised Paraparticle Theory'; International Journal of Theoretical Physics 26, pp.1141-1163.

French, S. (1995), 'The Esperable Uberty of Quantum Chromodynamics', Studies in History and Philosophy of Modern Physics 26, pp. 87-105.

French, S. (2014), The Structure of the World, OUP.

French, S. (2017), 'Building Bridges with the Right Tools: Modality and the Standard Model', in M. Massimi, J-W. Romeijn, G. Schurz, (eds.), Proceedings of EPSA2015, Springer, pp. 37-47.

French, S. (forthcominga) 'Doing Away with Dispositions: Powers in the Context of Modern Physics', in Dispositionalism: Perspectives from Metaphysics and the Philosophy of Science. ed. A. S. Meincke. Springer Synthese Library, Springer.

French, S. (forthcomingb), There Are No Such Things as Theories.

French, S. and Krause, D. (2006), Identity in Physics, Oxford University Press. 
French, S. and McKenzie, K. (2012), 'Thinking Outside the (Tool)Box: Towards a More Productive Engagement Between Metaphysics and Philosophy of Physics' with K. McKenzie, The European Journal of Analytic Philosophy 8, pp. 42-59.

French, S. and McKenzie, K. (2015), 'Rethinking Outside the Toolbox: Reflecting Again on the Relationship Between Philosophy of Science and Metaphysics', in T. Bigaj and C. Wuthrich (eds), Metaphysics in Contemporary Physics, Poznan Studies in the Philosophy of the Sciences and the Humanities, Rodopi, pp. 145-174.

French, S. and Saatsi, J. (2018), 'Symmetries and Explanatory Dependencies', forthcoming in J. Saatsi and A. Reutlinger (eds.), Explanation Beyond Causation, Oxford University Press, pp. 185-205.

Ladyman, J. Ross, D., et al. (2007) Every Thing Must Go: Metaphysics Naturalized, Oxford: Oxford University Press.

Lowe, E.J. (1998), The Possibility of Metaphysics: Substance, Identity and Time, Oxford University Press.

Massimi, M. (2018) 'Four Kinds of Perspectival Truth', Philosophy and Phenomenological Research 96, 342-359

Psillos, S. (2006), 'What do powers do when they are not manifested?' Philosophy and Phenomenological Research 72: 135-156.

Psillos, S. (2016), 'Broken Structuralism', Metascience 25 pp. 163-171.

Rettler, B. and Bailey, A. M., (2017), 'Object', The Stanford Encyclopedia of Philosophy (Winter 2017 Edition), Edward N. Zalta (ed.), URL = <https://plato.stanford.edu/archives/win2017/entries/object/>

Saunders, S. (2003), 'Physics and Leibniz's Principles', in Symmetries in Physics: Philosophical Reflections, K. Brading and E. Castellani, eds., Cambridge University Press, pp. 289-307.

Tegmark, M. (2006), “The Mathematical Universe”, Foundations of Physics 38, pp. 101-150.

Vetter, B., (2009), Review of Bird, Logical Analysis and History of Philosophy 8: 320-328.

Vetter, B. (2015), Potentiality: From Dispositions to Modality. Oxford: Oxford University Press. 